\title{
The Relationship between Culture and Communication within the Ecclesia
}

\author{
Samuiel Bâlc \\ Theological Baptist Institute Bucharest, Romania, samybalc@gmail.com
}

\begin{abstract}
Culture, communication and community are not separable from each other. In order to have proper relationships, culture plays a very important role as a means by which these relationships are expressed, but at the same time there must be adequate communication. Reflecting on the different ways in which the human being is understood is also very important. There is, as can be seen, an almost universal tendency to judge other cultures and communities based on someone's cultural predispositions. Thus, how to think, feel, communicate, and behave in a particular culture becomes good or bad, understandable or incomprehensible, acceptable or ridiculous, if they are in accordance with our "way of thinking, feeling," communicate and behave. In order to overcome many barriers and prejudices, it is especially important to know the relationship between culture and communication and the role they have within the ecclesial community. All this is outlined in a practical way in this article.
\end{abstract}

KEYWORDS: culture, communication, community, ecclesia, thinking

\section{Introduction}

The word culture, derived from Latin culture, itself derived from the verb colere (could be translated by building, taking care of, planting or cultivating) has many meanings. In 1952, Kroeber and Kluckhohn, limited to British uses, identified more than 160 definitions. The word culture usually refers to something that is created by human's intervention or derives from human activity: culture is thus cultivated (Gavreliuc 2011, 24). Culture is the set of ideas and forms of behavior acquired within a society, communities.

The cultural flow is not an unequivocal fact, which attests to the creative capacity of the masses to select, assimilate and shape the cultural phenomenon, giving it new valences and dimensions. [...] Only through the wide penetration of culture into the mass man becomes, in turn, a cultural agent, an active and conscious factor in the creation of his own history. (Bondrea 2006, 252)

The cultural phenomenon acquires new meanings with the progress of society, giving birth to mass culture, which is understood as an ensemble of socio-cultural, educational, preferences of the members of society. Mass culture reflects the processes and educational phenomena, the structure and functionality of the institutional cultural system, the efficiency of cultural action and the way in which human action manifests itself. It is, in the end, a form of valorisation of existence, part of the structure of a community. It is worth noting that human are subjected to a cultural pressure that can deform his reality. Man is an active being with a creative capacity, said Aurelian Bondrea (2006, 255-256), which must be taken into account in the process of disseminating culture, in the methods and forms that this process takes. So the cultural act must start from the premise of exerting such influence on man so that he feels the essential need to integrate into the process of culture as a participant in the selection and assimilation of culture.

A cultural value cannot therefore be achieved without the active participation of human. This has caused some to combat mass culture as it promotes the spectator/bystander's position, the spirit of imitation and manages less to transform human into an active factor in relation to the act of culture. Mass culture tends, from the perspective of some, to creating a type of human who only has the bystander position. Guy Rocher $(1970,111)$ observes that:

The ways of thinking, feeling and acting more or less formalized, which, being taught and shared by a number of people, serve in an objective and symbolic manner at the same time, the constitution of these persons in a particular and distinct community. However, this standardization does not make them all alike. Having certain margins of maneuver, they can form their own beliefs and identify with more or less unusual patterns. 
"Viewed from an individual perspective, culture is given by all the intellectual elements presented in a given spirit. The ensemble of these spirits thus expresses the culture of a society, said Bondrea $(2006,256)$. Culture is conceived, as well as a screen of knowledge that an individual designs for his sensations to reach perceptions." It can therefore be said that a particular form of culture imposes different value systems. Culture is perceived as a mold that determines the behavioral form.

According to Edward Taylor, "culture is a complex one, which includes knowledge, faith, art, morality, law, culture, and all the other skills and habits acquired by man as a member of society". (Ferreol 2005, 181) When talking about communication and culture within the Ecclesia, one thing to keep in mind is the possibility of mutual cultural enrichment. In this sense, Paul Ricoeur (1970) highlights that: "Far from seeing the input of past centuries as an intangible treasure, culture offers the possibility of a whole series of reinterpretations which, in their turn, keep alive, consolidate or update it, tradition and innovation not being antonymous but complementary."

Francois Dosse (1997) emphasized, on the other hand, that: "From the bottom, the world is indeed characterized by an extreme diversity of situations and populations whose systems of beliefs and practices change over time and space. This complexity urges us to be somewhat more modest in our estimates of interactions between cultures and development." Another author Raymond Williams defined the culture as:

\begin{abstract}
A particular way of life outlined by values, traditions, beliefs, material objects and territory. Culture is a complex and dynamic ecology of people, things, visions of the world, activities and ambitions that essentially reside, but are also changed by routine communication and social interaction. Culture is the context. It is the way we talk and dress, the food we eat and the way we prepare and consume it, the gods we invent and the ways we adore it, the way we share space and time, how we dance, the values we share with our children, and all the other details that make up the daily life. This view of culture means that no culture is inherently superior to another, and cultural wealth is by no means derived from the economic situation. Culture as everyday life is a deeply democratic idea. (Lull 1998, 75)
\end{abstract}

Culture is rooted - not only in race - but also in social class, culture being significantly differentiated by social classes. To explain such differences, American sociologist Herbert Gans tried to score both social class and culture in a concept he called "taste culture." (The taste culture refers to the cultural strata of a society that approximates the social classes of that society. Although it does not equate them, Gans discovers the significant parallel between taste and social class position.)

According to Bourdieu, the areas of cultural co-operation and characteristic modes of action are learned through social experience. But although people can internalize their position in the social space, these experiences are not determined by one's niche on a socio-economic scale and do not reflect it perfectly. What teaches a person on a cultural level is influenced, but not limited to, by the tastes and daily activities of people who occupy the same social class (Lull 1998, 78).

It must be remembered that we do not acquire cultural orientations and skills imitating the world around us. At present, culture not only encompasses traditional values and routine activities that make up the living environment, but also a wide range of symbolic resources. The quest for intercultural knowledge is conveyed by the magnitude of multiple causes. It is envisaged, according to Alin Gavreliuc (2011, 20-21), the presence of epistemological causes (stem from the discovery of cultural, social and historical variations in subject behaviors), causes of social and political nature (generated by social projective needs, such as contemporary identities), causes of a pragmatic nature, related to the need for organizational optimization (capitalizes on the potential of knowledge and action provided by identifying self-heterogeneity to a globalized world), as well as causes stemming from the universalization of social problems.

Considering that the world has now become a cultural diversity, it can be said that no action is possible in the social environment in general and in the organizational one, in particular, outside the knowledge of cultural conditioning of behaviors, values and people's attitudes. (Today, phenomena such as trafficking in human beings, terrorism, unemployment, emigration can no longer be isolated 
within political boundaries. They are transcultural and call for an appropriate, innovative response that goes beyond the limitations of purely speculative concepts built at the intranational level.) From Gavreliuc's $(2011,24)$ point of view, "the term culture is often used in current language in a nonspecific way to describe a rather diffuse conceptual area, such as evocations in the institutional language of organizational culture or art and culture. What all these concepts have in common is the qualification of culture as an abstract entity, involving a series of artifacts collectively shared, behavioral patterns, values, or other artificial concepts that, taken together, form the cultural ensemble".

H. Triandis $(1972,8)$ introduced the concept of "subjective culture," or "a characteristic way of perceiving the social environment," which appears to be common to a culture. Culture is therefore in that a set of essential values and attitudes patterns that underpin functional social behaviors and which are transmitted integrated through specific socializing agents (Gavreliuc 2011, 25). According to Gavreliuc $(2011,25-27)$, culture can be defined through several factors that characterize it:

- Attitudinal and behavioral attitudes ("what happens," "what is right"), socially learned and assumed by an implicit logic of the order (It is worth mentioning, in this register, the convergence or the divergence between attitude and behavior, with the possibility of duplication).

- The ensemble of existentially patterns (expressed through the anthological verbs "to be" or "to survive / become." Communities centered on "having" are typical of societies for which it is fulfilled means to have "objects," "experiences" and "relationships" as diverse and "fashionable" as those centered on "being" the record of personal fulfillment through authentic, profound experiences, associated with traditional morals. Communities in which the subjects are guided in their existential strategies by "survive" their life through a form of social autism to the limit of subsistence, are not capable of medium and long-term strategies, the only and decisive concern being the "saving" day by day "from the collective impasse, everyday misery and lack of social hope. Those in his "become" register are capable of medium and long-term plans - from setting the destination of future holiday leave, buying consumer goods, housing construction, or initiating a business initiative - have a committed social hope (it is worthwhile to engage in community action), they drive, feel, and know that they "deserve" social, economic, political initiatives because they will have a stimulating echo, enhancing their community resources (Gavreliuc, 2011, p. 26).

- Political institutions structured according to who orders and who submits (Every society is built on hierarchical relationships that balance naturally by articulating an implicit social contract and power networks).

- Active lights, consisting of default or explicit communication codes.

- The rules governing interpersonal relations based on opening or, on the contrary, on interpersonal closure (A privileged dimension that shapes interpersonal expressiveness is selfmonitoring).

- Division of work according to independent status variables (age, ethnicity, environment).

- Housing styles, particularly by illustrating the public / private relationship.

- Public employment procedures designating different types of community expression.

L. A. White (1947, 686-698) defines culture (seen as continuous, cumulative, collective) as the totality of symbolic behaviors (languages and codes of communication) that make it possible to transform the "wisdom" of the community (of Community science) in technical forms transmitted from generation to generation through a certain symbolic technology.

For Moore and Lewis (1952, 380-388), "culture, which is rather hidden, is intangible, a kind of label for very diverse categories of phenomena that designate knowledge, skills and information learned.” From the perspective of C. Kluckhohn and A.L. Kroeber (1952):

Culture consists of explicit and implicit patterns of behavior, acquired and transmitted through symbols, constituting the distinctive achievements of human groups, including their embodiment in 
artifacts; the core of culture is traditional ideas (for example historically and selected ones) and, in particular, their values attached; cultural systems can be considered, on the one hand, products of action and, on the other hand, conditional elements of future actions.

In the conception of C. Ember and M. Ember (1985): "culture is formed, on the one hand, from learned attitudes and behaviors, as well as from characteristic beliefs of a community, and on the other, from the shared tradition of society. Barnlun and Araki (1985, 9-26), describe the culture from a behaviorist perspective as what is found directly in the manifest behaviors of the people while C. Boesch (1991, 81-90) considers it a "field of action, the content of which is represented by objects made by man (such as the institutions, ideas, myths)." "Culture shapes us, but in turn we are remodeling culture, we are not passive receivers, but we rebuild the environment, according to our interests and values" (Shweder 1990, 399-416).

For Spencer-Oatey $(2000,4)$, "Culture is an unclear set of attitudes, beliefs, norms of behavior, assumptions, and basic values that are shared by a group of people and that influence the behavior of members and their own interpretation of the meaning of others' behavior." The role of culture is, therefore, both a factor of influence on behavior and an interpretive factor of a person's conduct. From Irina Nicolau's $(2001,20)$ point of view, "Culture is nothing else but the intergenerational transfer of community knowledge, of those essential meanings and effective ways of acting that can provide natural functional solutions in routine or staggered situations." In this way, "an useful idea, good behavior, a customable habit can be adopted by more and more individuals and can become an important element of culture". Triandis $(2002,135,136)$ ighlights that:

Cultures develop conventions for gathering information and determine the value of each information. For example, people in hierarchical cultures tend to retain hints about hierarchy rather than aesthetics. Those in individualist cultures will observe and retain their own selfinformation as opposed to the subjects in collective cultures that retain more information about the collective self and the social networks in which they are inserted.

Particularly interesting is how Hofstede (1980) described the culture. According to him:

Culture is a collective mental programming that forces us to accept the essential presumptions of society together with the members of the nation or group we are part of, but not with the components of other groups or nations. Each of us is the bearer of thought patterns, feelings and potential manifestations that have been acquired over the course of our lives. These ways of thinking, feeling and acting are mental programs "mind software."

Although the definitions are very numerous, most of the field scholars agree that: "the term culture refers to a socially inherited ensemble and transmitted by conducts and symbols of significance, a system of representations and a system of language that is expressed in symbolic forms, a means by which people communicate, perpetuate and develop their knowledge and attitudes towards life" (Dasen 1999, 85).

Associated with the environment of communication, culture designates the predominant system of beliefs and values that they share and in which members of the community work. From Schein's $(2004,13)$ perspective:

Culture can also be defined as a pole, latent manifestation, which clarifies its composition and its visibility. Therefore, the values, norms and behaviors shared and activated within an organization can be accessed "on the surface", where the explicit culture is manifested through the structure of the organization's leadership and through the "rhetoric" of formal decisions issued by it (bulletins, notifications, or "in depth", where the default culture is closer to reality, made up of unsubstantiated assumptions and requirements on the basis of which employees decide what is important, what are the ways to follow, what are desirable behaviors. According to this vision, we also have two possible types of cultures, depending on the committed vitality. A "strong" culture is one in which the implicit premises harmonize with explicit ones. A "poor" culture is the one in which the implicit register contradicts the explicit one. Moreover, the function of culture in the life of the group changes with its maturation, and when it comes to analyzing the evolutionary mechanisms of culture, it suggests the idea of a "life cycle". 
According to McGrew (1992), culture brings together eight traits that are assumed and promoted exclusively by the human being, namely:

- Innovation - producing new behavioral, adaptive responses based on new attitudes and value options.

- Dissemination - purchase from "inventor" and transfer to "the other" through an interdisciplinary process.

- Standardization - elaboration of consistent and referential patterns through an intergenerational process.

- Durability - preservation over time within a generation.

- Diffusion - spreading from one group to another through an intergroup process.

- Tradition - persistence from the innovator to the next generation through an intergenerational process.

- Insubstantial - transcends subsistence, not depending on the biological register.

- Naturalness - patterns are naturally born, responding to human and social needs, following adaptive demands.

Geertz $(1973 / 2001,89)$ described culture as the historically transmitted pattern of meanings embodied in symbols, providing answers to the problems of life, as well as a means or patterns of interaction with the environment, interrelation, orienting the individual through a system of religious and folkloric traditions. On the other hand, Bozian (2004) points out that: "Cultural characteristics stand out by comparison with other cultural types." Considering that the difference between cultures is not of axiological nature, one cannot speak of superior or inferior cultures, but of different cultures.

A special role of culture is to give meaning to experience, to attribute a sense of experience based on the values of society and to include the social destiny of each person in the community. While multicultural communities are diverse social realities in which different ethnic, confessional, generational layers join in a determined historical context, intercultural communication includes ethnic, religious, cultural groups that not only share the same space, but also learn to cultivate open relationships of interaction, respecting the values, traditions and lifestyles of each.

\section{The link between culture and communication}

Speaking about intercultural communication, which he sees as a communicative relationship between different cultures, Dumitru Zaiţ $(2002,55)$ highlighted the following:

Communication can be accepted as a complex relationship that is established between individuals or groups through a hereditary learned or inherited symbolism that enables messages to be transmitted and received in a certain context, at a given time and under certain spatial circumstances. It has, but is not always, an objective or subjective purpose, causing changes in actions or behaviors in desirable or unwanted, void or involuntary, positive or negative ways through the states that the interpretations of messages transmitted to the receptors induce. Accumulations produced at communication system are dominated by the culture in which the individual or group is born and evolves. Communication relations are therefore culturally dependent and therefore always interpretable in a certain context.

At intercultural communication, there is an interactive relationship that brings together individuals or different groups belonging to cultural environments that have particular aspects at the level of the symbolism and the meanings designated by words, behaviors, customs, gestures, etc.

According to Giddens (2001, 82-83), "Social interaction requires many forms of non-verbal communication (sometimes called "body language"), the exchange of information and meanings through facial expressions (mimic) gestures and movements of the body. [....] Like facial expressions, body gestures and positions are used continuously to fill expressions as well as to convey meaning when no word is spoken. [...] The non-verbal impressions we transmit, often inadvertently, indicate that what we are saying is not exactly what we mean." 
Language is known to be essential to social life. The way people use language in their personal interaction is equally important. Often it is possible to understand what is conveyed in a conversation only when we know the social context, which is not expressed in words. An example of this is the following conversation:

A. I have a 15 year old girl.

B. Well, it's nothing.

A. I also have a cat.

B. Oh, I'm sorry.

What can be supposed to happen, listening to this conversation? What is the relationship between speakers? If it is known that this is a conversation between a potential tenant and an owner, the conversation would be understandable. Some owners are accepting people with children, but not animals. So, if the social context is not known, the answers of the individual B seem to have nothing to do with the statements of the person A. The conclusion is that part of the meaning is in words, and the part is in the way in which the social context structures what is said. It can therefore be said that speech is an essential element of every area of a community's life. As for the community, Cohen highlights two fundamental aspects:

Members of a group of individuals forming a community have something in common with everyone else, on the one hand, and yet, on the other hand, they are distinguished in a significant way from members of other groups. Thus, the community seems to simultaneously involve similarity and difference. The community actually exists in the minds of its members. By extension, the reality of community boundaries lies in thinking, in the meanings that people attach to them, and not in their structural forms. In a community, even if its structural borders remain intact or not, the reality of the community lies in the perception of members about the vitality of her culture. People build the community in a symbolic handbook, making it a resource of significance, a depositor of it, and an identity referent. (Zamfir 2007, 120)

An ecclesial community cannot, therefore, communicate effectively by ignoring the culture, because the process of communication cannot be separated from culture. Despite the differences in a community, communication can be achieved in an effective way as it seeks common elements that define the community.

\section{Conclusion}

Just as culture can influence communication within the Ecclesia and communication can contribute to the development of culture among the ecclesial community; the two areas, culture and communication cannot be separated. Equally, for human in particular, as well as the community, culture represents the specific environment of existence. Culture encompasses values sets in which learning efforts and human attitudes towards what surrounds are manifested.

The process of assimilation and application of values can be expressed through various social actions, but also through communication. From this perspective, communication is a social action that involves the entire behavior of human. Thus, communication has a fundamental role in shaping life and highlighting cultural patterns within society and the ecclesial community.

You cannot know a community, you cannot get closer to its culture if you do not make an effort to know its communication possibilities and opportunities. Communication, in its various forms, has allowed throughout history to add cultural values, thus conferring to humankind a cumulative character. Appropriate communication within a community is therefore not limited to information transmission only, but must also take into account an understanding of the wishes, needs and the culture of the other. There is therefore a close link between culture and communication that can and must be used for the development of the ecclesial community.

\section{References}

Barnlun, D. C. and S. Araki. 1985. „Intercultural encounters: The management of compliments by Japonese and Americans." Journal of Cross-Cultural Psychology 16 (1): 9-26.

Boesch, C. 1991. „Symbolic communication in wild chimanzees?” Human Evolution 6 (1): 81-89. 
Bondrea, A. 2006. Sociology of Culture. Bucharest: Romanian Publishing House of Tomorrow.

Bozian, M. 2004. Dynamics of identity and a culturative processes. Intercultural study in Romania and the US. UVT License Timişoara.

Dasen, P., C. Perregaux and R. Micheline. 1999. Intercultural education. Iaşi: Polirom Publishing House.

Dosse, F. 1997. L'Empire du Sens. L'humanisation des sciences humaines. Paris: La Decouverte.

Ember, C. R. and M. Ember. 1985. Antropology, (ed.a 4-a). New York: Prentice - Hall, Englewood Cliffs.

Ferreol, G. and G. Jucquois. 2005. Dictionary of alterity and intercultural relations. Iaşi: Polirom Publishing House.

Gavreliuc, A. 2011. Intercultural Psychology. Romanian theoretical and diagnostic references. Iaşi: Polirom.

Geertz, C. 1973/2001. The interpretation of cultures. New York: Basic Books.

Giddens, A. 2001. Sociology. Bucharest: Edit. BIC ALL.

Hofstede, G. 1980. Culture's consequences: International differences in work-related values. Beverly Hills: Sage.

Kluckhohn, C. and A. L. Kroeber. 1952. Culture: A critical review of concepts and definitions, apud N. J. Adler, International dimensions of organizational behavior. Cambridge: Peabody Museum.

Lull, J. 1998. Information handling, media-communication. Philippe de Târg: Antet XX Press.

McGrew, W. C. 1992. Cimanzee material culture: implications for human evolution. Cambridge: Cambridge University Press.

Moore, O.K. and D. J. Lewis. 1952. „Learning theory and culture.” Psychological Review 59 (5): 380-388.

Nicolau, I. 2001. Tangle-Haze of ethnology and many more. Bucharest: Ars Docendi Publishing House.

Ricoeur, P. 1970. Historie et verite. Paris: Espirit Publishing House.

Rocher, G. 1970. Introduction to general sociology, vol. 1. Paris Seuil: L'Action Social.

Schein, E. 2004. Organizational culture and leadership, (ed. 3-a). New York: Wiley Publishers.

Shweder, R.A. and M.A. Sullivan. 1990. „The semiotic subject of cultural psychology.”, in L. A. Pervin (ed), Handbook of personality theory and research. New York: Guilford.

Spencer-Oatey, H. 2000. Culturally speaking: managing rapport through talk across Cultures. Londra: Conitnuum.

Triandis, H. C. 1972. The analysis of subjective culture. New York: John Wiley.

Triandis, H.C. and E.M. Suh. 2002. "Cultural influences on personality." Annual Review of Psychology 53: 133-160.

White, L.A. 1947. „Culturalogical vs psychological interpretations of human behaviour.” American Sociological Review 12(6): 686-698.

Zaiţ, Dumitru. 2002. Intercultural management. Valorisation of cultural differences. Bucharest: Economic Publishing House.

Zamfir C., and S. Stănescu. 2007. Encyclopedia of social development. Iași: Polirom Publishing House. 